For submission to:

\title{
Tyrol Prostate Cancer Demonstration Project: Early Detection, Treatment, Outcome, Incidence and Mortality
}

\author{
Georg Bartsch (1)* \\ Wolfgang Horninger (1)* \\ Helmut Klocker (1) \\ Alexandre Pelzer (1) \\ Jasmin Bektic (1) \\ Wilhelm Oberaigner (2) \\ Harald Schennach (3) \\ Georg Schäfer (4) \\ Ferdinand Frauscher (5) \\ Mathieu Boniol (6) \\ Gianluca Severi (7) \\ Chris Robertson (8) \\ Peter Boyle $(6,9)$
}

On behalf of the Tyrol Prostate Cancer Screening Group

* Both authors contributed equally to this manuscript

1. Department of Urology, University of Innsbruck, Austria

2. Tyrol Cancer Registry, Innsbruck, Austria

3. Institute of Immunology and Transfusion Medicine, University of Innsbruck, Austria

4. Department of Pathology, University of Innsbruck, Austria

5. Department of Radiology, University of Innsbruck, Austria

6. International Agency for Research on Cancer, Lyon, France

7. Victoria Cancer Council, Melbourne, Australia.

8. Strathclyde University and Health Protection Scotland, Glasgow, Scotland

9. Address for correspondence: Peter Boyle PhD DSc (Med), FMedSci, International Agency for Research on Cancer, 150 cours Albert Thomas, 68372 Lyon cedex08, France. Fax +33472738575 and e-mail <director@iarc.fr> 


\section{ABSTRACT}

\section{BACKGROUND.}

The effectiveness of a well-controlled programme of early detection and treatment of prostate cancer can be evaluated in the population of Tyrol, Austria, where such a program of early detection and treatment was initiated in 1988 and where Prostate Specific Antigen (PSA) testing was offered for free to all men aged 45 to 75 years from 1993.

\section{METHODS}

Comparison of prostate cancer mortality rates in Tyrol and the rest of Austria was accomplished through a generalised additive model. A piecewise linear change point Poisson regression model was used to compare mortality rates in Tyrol and the rest of Austria. Standardised mortality ratios were calculated with reference to the mortality rates in 1986-90.

\section{FINDINGS}

$86.6 \%$ of eligible men have been tested at least once since 1993. Cancer deaths in Tyrol in 2005 were 54\% (95\% CI $(34 \%, 69 \%))$ lower than expected compared to $29 \%(95 \%$ CI $22 \%, 35 \%)$ in the rest of Austria. The decreasing trend in prostate cancer mortality was significantly greater in Tyrol compared to the Rest of Austria ( $p$ 
$=0.001)$. A significant migration to lower stage disease occurred and radical prostatectomy was associated with low morbidity.

\section{INTERPRETATION}

In the Tyrol region where treatment is freely available to all patients, where widespread PSA testing and treatment with curative intent occurs, there is a reduction in prostate cancer mortality rates which is significantly greater than the reduction experienced in the rest of Austria. This reduction in prostate cancer mortality is most likely to be due to early detection, consequent down-staging and effective treatment of prostate cancer. 


\section{INTRODUCTION}

Since prostate-specific antigen (PSA) testing for prostate cancer became available, both incidence and mortality rates have changed profoundly; between 1989 and 2002, the age- standardized incidence rate of prostate cancer in the United States increased by $21.3 \%{ }^{1}$. Prostate cancer is now the most frequently diagnosed noncutaneous cancer in Europe and in the United States ${ }^{2}$. Widespread implementation of prostate cancer screening in the United States has led to stage migration with more cancers being detected at a lower stage. There has been a $75 \%$ reduction reported in the proportion of cases presenting with metastatic disease at diagnosis and a corresponding 32.5\% decrease in the age-adjusted mortality rate from 1993 to 2003 3,4 .

Randomized, controlled trials evaluating the efficacy of PSA and digital rectal screening in reducing prostate cancer mortality are underway, ${ }^{5,6,7}$ but the results will not be available for several years. Furthermore, the randomized design of these trials may be compromised if non-adherence to the assigned intervention group is extensive i.e. widespread contamination of the control group due to members seeking PSA testing. ${ }^{8}$ The consequences on the statistical power of these trials could be considerable ${ }^{9}$. 
It is essential to separate the question of efficacy of screening from the effectiveness of a well-controlled screening and treatment programme. The present study reports the incidence and mortality rates of prostate cancer in the Federal State of Tyrol, Austria, where PSA-testing started in 1988 and has been made freely available to the population of men 45 to 75 years of age since 1993. Incidence, stage migration and mortality rates of the Tyrol study are reported. The issues of diagnoses - how PSA can be used intelligently, the value of anatomical radical prostatectomy and the problem of over-diagnosis are discussed in regard to the qualitative effects of prostate cancer screening. PSA testing was not available free of charge in the rest of Austria, although it was used, probably evolving in a similar manner to use in many western countries. Comparison of mortality rates between Tyrol and the rest of Austria allows evaluation of the outcome of this natural experiment.

\section{METHODS}

\section{Study Design}

Since 1988, early prostate cancer detection has been promoted by the Department of Urology of the University of Innsbruck, Austria, using both PSA and digital rectal examination (DRE) in the diagnostic workup of asymptomatic healthy men. Since 1993, this early prostate cancer detection program has been carried out in the Federal State of Tyrol (one of the nine Federal States of the Republic of Austria) with prospective data collection and documentation, as well as with the development of 
an associated biorepository. Details of all individual PSA test results and biopsies, with a unique identifier for the individual man, are recorded so that the cancer registry in Tyrol is able to ascertain which men have had at least one PSA test and hence calculate the numbers of men who have not been tested.

Tyrol is an alpine region in Western Austria with, at the 1991 census, 631,410 inhabitants $(324,161$ women and 307,249 men) in an area of 12,647 square kilometers. At the same census, the total population of Austria was 7.81 million with 4.05 million women and 3.76 million men. Tyrol is dominated by the mountains of the Central Alps, and the distances to Innsbruck, the capital, where the central health care unit is located, are not great (infrequently more than 100 kilometers). This geographic situation, as well as the willingness of the general population to participate in preventive medical programs, is well suited for a state-wide mass screening program with PSA as the first-line screening test for the early detection of prostate cancer.

PSA testing was made freely available by the Social Insurance Company of the Federal State of Tyrol and the University Hospital of Innsbruck to all men aged 45 to 75 years who were inhabitants of Tyrol. Of the 307,249 male inhabitants in 1993, 86,067 were between 45 and 75 years of age. All men in this age range were advised and encouraged to undergo PSA testing; the information of advantages and disadvantages was distributed to all Tyrolean men by press, radio, and television. All these releases were approved by the review board of the prostate center at the department of Urology, University of Innsbruck. 
The screening demonstration project was performed in collaboration with general practitioners, medical examiners, urologists, medical laboratories, and the Tyrol Blood Bank of the Red Cross. The study protocol was approved by the review board of the prostate center at the Department of Urology, University of Innsbruck. Informed consent was obtained from all volunteers participating in the program. All co-workers were fully informed of the guidelines for withdrawal, storage, and shipping of the blood samples. PSA was assessed immediately on arrival of the blood or serum sample. All volunteers and/or referring physicians were informed about the results in writing. In the case of elevated PSA levels, the volunteers were invited to undergo additional urologic evaluations at no cost, and the men with normal PSA levels were invited to have a repeated PSA test 6 or 12 months later. At the time of drawing blood for PSA measurement, no DRE was performed.

PSA testing was provided free of charge to men between 45 and 75 years old and to younger men (40 years) with a family history of prostate cancer. In all laboratories, the PSA concentration was assessed using the Abbott IMX assay.

\section{Diagnosis}

From September 1993 to September 1995, age-referenced PSA levels ${ }^{10}$, (40-49 years: $0-2.5 \mathrm{ng} / \mathrm{ml}, 50-59$ years: $0-3.5 \mathrm{ng} / \mathrm{ml}, 60-69$ years: $0-4.5 \mathrm{ng} / \mathrm{ml}, 70-79$ years: 0-6.5 $\mathrm{ng} / \mathrm{ml}$ ) in combination with percent free PSA of less than $22 \%$, were used as the criteria for recommending biopsy. Since October 1995, lower PSA levels ${ }^{11}$ 
(45(40)-49 years: $0-1.25 \mathrm{ng} / \mathrm{ml}, 50-59$ years: $0-1.75 \mathrm{ng} / \mathrm{ml}, 60-69$ years: $0-2.25$ $\mathrm{ng} / \mathrm{ml}, 70-79$ years: $0-3.25 \mathrm{ng} / \mathrm{ml}$ ), together with percent free PSA levels of less than $18 \%$ were used. In March 1996, an artificial neural network was constructed, using total PSA, free PSA, age, DRE and TRUS variables. Using this neural network the probability of having cancer could be estimated. In 2005, the concept of PSAVelocity ${ }^{12}$ was incorporated in the diagnostic workup to further enhance the specificity of the program (fig.1).

All men who met the above-mentioned biopsy criteria, were invited to undergo additional urologic evaluation, including DRE and trans-rectal ultrasound-guided biopsies of the prostate. Urologists performed the DRE and transrectal ultrasound examinations. Sextant biopsies were initially made using ultrasound guidance with an automatic biopsy gun; since 1995, 10 systematic biopsies have been performed, and since 1998 additional contrast enhanced color Doppler-targeted biopsies have been performed by specialized uroradiologists ${ }^{13}$ (fig. 2).

Treatment of men with prostate cancer

In men presenting with a clinically localized tumor (clinical T1 and T2 lesions), surgical removal of the prostate was recommended. In 1988, anatomical radical prostatectomy ${ }^{14}$ was introduced into the therapeutic concept for localized prostate cancer

Patients with a clinical stage T3 lesion were treated with external beam radiotherapy 
alone. Since 2001, androgen-deprivation therapy was used in combination with external beam radiation therapy (70.2 Gy, single fraction $1.8 \mathrm{~Gy}$, four-field technique). Patients with metastatic disease were treated with androgen deprivation therapy.

The Austrian Social Insurance System as well as the establishment of a prostate center at the Department of Urology ensured that every man diagnosed with prostate cancer has access to medical care of the highest quality available in both diagnosis and treatment free of charge.

\section{Clinical follow up}

All surgically treated patients had a routine follow-up by the treating physician. 1517 patients (91.2\%) had a follow-up of at least one year and were specifically questioned about their urinary continence and any complications of treatment by an independent investigator. Since 2000 the potency status of 512 men who were potent prior to the operation and younger than 65 years was also assessed by an independent investigator. Continence was defined as no need for protective pads, potency was defined as the ability of having intercourse 2 years after surgery with or without PDE5 - Inhibitors. 
Population-based data on cancer incidence have been available from the Tyrol Cancer Registry, since 1988, and also from the Austrian National Cancer Registry. Cancer mortality data have been available, independently, from the Austrian Central Statistics Office since 1970. Underlying cause of death was attributed from the death certificates of all deaths in Austria by the Central Statistical Office in Vienna, where they were unaware of the study being performed in Tyrol. Annual numbers of cases and population estimates are available in five-year age categories. PSA tests were available at no charge for men aged 45 to 75 years, although PSA testing was used among men in other age groups. Men who were 40 to 44 years of age in 1993 were eligible for screening during the follow-up interval of this study.

During the five year study period, it was assumed that PSA screening could affect death rates in the age group beyond screening age range (75 to 79 ); therefore, truncated mortality rates were considered to age 79 . Incidence and mortality rates for the age range of 40 to 79 years of age were calculated, employing the World Standard Population as reference ${ }^{15}$.

The principal hypotheses to be tested can be expressed as follows: (i) do prostate cancer mortality rates in Tyrol decrease from 1993; (ii) do trends in prostate cancer mortality rates in Tyrol differ from those in the rest of Austria from 1993 onwards. Trends in the mortality rates, for age group, $i$, and year, $y_{1}$ in Tyrol and the rest of Austria were compared within a Poisson regression model. 


$$
\begin{aligned}
\log \left(\text { rate }_{i y}\right)= & \beta_{0 i}+\beta_{1}(y-1993)+\beta_{2}(y-1993) I(y \geq 1993)+ \\
& \beta_{3} \text { Tyrol }+\beta_{4} \text { Tyrol }(y-1993)+\beta_{5} \operatorname{Tyrol}(y-1993) I(y \geq 1993)
\end{aligned}
$$

This is a "change-point" model in which the term $I(y \geq 1993)$ is an indicator which permits there to be a different slope from 1993 onwards compared to before 1993 . The parameter $\left(\beta_{0 i}\right)$ gives the estimated log mortality rate in the rest of Austria in 1993 for age group $i$, and $\beta_{3}$ represents the difference from this value in Tyrol. A priori, no difference is anticipated in any age group. The slope of the relationship between log mortality rates and year is given by $\beta_{1}$ in the rest of Austria and $\beta_{1}+\beta_{4}$ in Tyrol; thus $\beta_{4}$ represents the difference in slopes, prior to 1993 . The parameter $\left(\beta_{2}\right)$ gives an estimate of any change in slope from 1993 onwards compared to 1992 and before in the rest of Austria. If there is no change then the estimated value will be about zero, if there have been treatment advances then a negative estimate would be expected. In the Tyrol the change in the slope from 1993 onwards is given by $\beta_{2}+\beta_{5}$. Thus $\beta_{5}$ is the crucial parameter in the analysis as it measures the different slope in the Tyrol compared to the rest of Austria from 1993 onwards. The goodness of fit of the model was established on the basis of residual plots and hypothesis tests were based on changes in the deviance ${ }^{16}$. In particular, interaction tests were used to test if the parameters $\beta_{1}, \ldots, \beta_{5}$ depended upon age group. These interactions tests are secondary hypotheses and the effects are only included in the final model if significant at the $1 \%$ level.

A possible criticism of this analysis is that it assumes a change point model with 
linear trends for year. As there is a much longer follow up relative to our previous analysis we relax this assumption using a generalised additive mode ${ }^{17}$ where the linear trends are replaced by smooth splines.

$\log \left(\right.$ rate $\left._{i y}\right)=\beta_{0 i}+s_{1}(y-1993)+\beta_{3}$ Tyrol $+s_{2}($ Tyrol $(y-1993))$

In this model $s_{1}()$ represents the trend in the rates in the rest of Austria, while $s_{2}($ ) represents the trend in Tyrol. All statistical analysis was carried out using Splus $7.0^{18}$.

As previously reported ${ }^{19}$, the estimated benefit of the mass screening program was calculated by comparing the observed and expected numbers of prostate cancer deaths in Tyrol and by comparing the prostate cancer mortality trends in Tyrol with the rest of Austria. The expected numbers of deaths for each year in Tyrol were calculated using the age specific averages of the rates from 1986 to 1990 as the reference. This calculation was carried out for men aged 40-79 and for men aged $80+$.

\section{RESULTS}

During 1993, when the Tyrol Prostate Cancer Demonstration Project was formally launched, $11.0 \%$ of Tyrolean men in the age range of 45 to 75 years had undergone PSA screening, and $86.6 \%$ of eligible men have been tested at least once during the 
study period. From 1988 to 2005, 454,356 PSA measurements were performed in all laboratories in the county of Tyrol (table 1). About $85 \%$ of all volunteers who, according to reference levels used at the time of their test, had an elevated PSA level, consented to additional evaluation, including DRE, transrectal ultrasonography (TRUS), and needle biopsy of the prostate.

From 1993 to 2005, 7074 TRUS-guided needle biopsies were performed at the Innsbruck University Hospital, and prostate cancer was detected in $24 \%$ of men with a PSA between 2 and $4 \mathrm{ng} / \mathrm{ml}$ and $40.2 \%$ with a PSA between 4 and $10 \mathrm{ng} / \mathrm{ml}$. The morbidity associated with TRUS-guided biopsy was low; major complications were seen in fewer than $1 \%$ of patients, and $0.5 \%$ of patients required hospitalization, most commonly for fever. Among patients diagnosed with $\mathrm{T} 1, \mathrm{~T} 2$ disease, $89.3 \%$ were treated with anatomical radical prostatectomy, 5.7\% were treated with brachytherapy and $4.7 \%$ were treated with external beam radiotherapy; $0.3 \%$ of patients were managed with a watchful waiting protocol.

The great majority of radical prostatectomies were performed at the Department of Urology of the University of Innsbruck, Austria. Between 1988 and 2005, 1765 radical prostatectomies were performed mostly by two surgeons (G.B., W.H.). Radical prostatectomy was associated with a low morbidity rate; the 30-day mortality was zero, and none of the patients suffered a ureteral injury. The rectal injury rate decreased from $0.6 \%$ before the year 2000 to $0.1 \%$ thereafter. Of the patients, $0.7 \%$ had postoperative bleeding requiring intervention. One year after surgery, 
$95.1 \%$ of men had recovered urinary continence (no pads) and erectile potency was preserved in $78.9 \%$ of men younger than 65 years of age (table 2).

The incidence rate of prostate cancer in men aged 40 to 79 years in Tyrol increased from 1988 until 1999/2000 and has remained essentially constant since. In the Tyrol the incidence rate of organ-confined disease (clinical stage $\mathrm{T} 1-\mathrm{T} 2, \mathrm{M} 0$ ) increased from 1988 until 2000 when the rate leveled off. In the rest of Austria the incidence rate for T1-T2, M0 prostate cancer, which was lower than that in the Tyrol from 1990, has increased gradually and in 2003 was at the same level as Tyrol (fig 3). The incidence of metastatic prostate cancer (M1) was lower in the Tyrol, especially since about 1995/6, but there is now evidence that the rates are converging (fig 3).

The age standardised rates (World Standard Population weights for ages 40-79) and fitted values of the additive model are shown in figure 4 (a) with those from the piecewise linear model in figure 4(b). In both cases there is evidence of a good agreement between the model and the observed age standardised rates. The deviance test of the more restrictive piecewise linear change point model against the additive model yields a non significant change of deviance of 2.95 on 4.0 degrees of freedom suggesting that the simpler piecewise linear model is an adequate description of the trends. Of note from the additive model, figure $4(a)$, is that the general trend of the rates in the rest of Austria is of a smooth curve peaking around 1990. Prior to 1990 there was a similar trend in Tyrol as in the rest of Austria but in the last 10 years, especially the rate of decrease of the mortality rates has been 
much steeper in Tyrol compared to the rest of Austria. The predicted line in Tyrol is lower than that for the rest of Austria from 1995 onwards.

Using the piecewise linear model, figure 4(b), there was no evidence of any interactions between age group and the effects of the comparison between Tyrol and the rest of Austria - Intercept in Tyrol in 1993, $\beta_{3}, \mathrm{p}=0.29$; slope in Tyrol prior to 1993, $\beta_{4}, \mathrm{p}=0.50$; slope in Tyrol after 1993, $\beta_{5}, \mathrm{p}=0.35$. There was some evidence that the overall trends in the age groups were not parallel - trend prior to $1993, \beta_{1}$, $\mathrm{p}=0.04$; trend after $1993, \beta_{2}, \mathrm{p}=0.01$. These interactions are not important as regards the main comparison between Tyrol and the rest of Austria and are ignored in the remainder. The interactions manifest themselves with slightly weaker trends over time among those aged 40-54 (where there are comparatively few deaths), compared with those aged 55-79.

There is no evidence that the trends in the rates in Tyrol and the rest of Austria before 1993 are significantly different $\left(X^{2}=0.42,1\right.$ degrees of freedom, $\left.p=0.52\right)$. In Tyrol the log mortality rates increased at a rate of 0.0093 (standard error 0.0043 ) per year while in the rest of Austria the increase was 0.0065 (s.e. 0.0011 ) per year. Furthermore, in 1993, there was no evidence of any difference between the estimated rates in the two regions $(p=0.16)$. From 1993 onwards there is strong evidence of a decrease in mortality in Tyrol $\left(X^{2}=39.2,1\right.$ degree of freedom, $p<$ 0.0001 ) where the log mortality rates have decreased at a rate of 0.0763 (s.e. $0.0122)$ per year, corresponding to a yearly reduction in mortality rate of $7.3 \%(95 \%$ CI $5.1 \%, 9.5 \%)$. In the rest of Austria there is also a significant decrease in the log 
mortality rates of 0.0324 (s.e. 0.0032 ) per year, corresponding to a decrease of $3.2 \%$ per year $(95 \%$ CI $2.6 \%, 3.8 \%)$ in the mortality rate. There is very strong evidence that the decrease from 1993 in Tyrol is significantly greater than the decrease in the rest of Austria $\left(X^{2}=12.3,1\right.$ degree of freedom, $\left.p=0.001\right)$.

Although, there were no statistically significant differences between Tyrol and the rest of Austria prior to 1993 the fitted value in Tyrol in 1993 is slightly higher than in the rest of Austria (see figure 4), and this may have some implications for the change in the slope. To investigate the effect of this we constrain the line before 1993 to be exactly the same in Tyrol as in the rest of Austria. This is achieved by setting $\beta_{3}$ and $\beta_{4}$ both equal to zero in the model. Now the rate of increase in the log mortality rates is 0.0067 (s.e. 0.0011 ) per year which is very similar to that for the rest of Austria above as Tyrol is a small part of Austria. In the rest of Austria the rate of decrease from 1993 onwards is 0.0332 (s.e. 0.0031) per year while in the Tyrol it is 0.0651 (s.e. 0.0072 ) per year. The test statistic for the comparison of the slopes from 1993 onwards is $X^{2}=21.08(p<0.0001)$.

The standardized mortality ratios in Table 3 demonstrate a reduction in the number of prostate cancer deaths, among men aged 40-79, relative to those expected on the basis of the age specific rates in the immediate pre-screening years (1986-90). In 2005 in Tyrol there was a 54\% (95\% Confidence Interval, 34\%, 69\%) reduction compared to $29 \%(95 \% \mathrm{CI}, 22 \%, 35 \%)$ in the rest of Austria. Among men aged 80 or over in the Tyrol, there was no evidence of an increase in prostate cancer deaths from 1991 onwards. Indeed, there were 36\% (95\% CI, 10\%, 56\%) fewer prostate 
cancer deaths than expected in 2005. In the rest of Austria there was evidence of an increase in the number of prostate cancer deaths among men 80 or over from 1995 to 2003 associated with the increase in the number of men in this age group.

In the period of 1996 to 2005, there were 567 expected (based on pretesting rates from 1980 to 1990), but only 347 observed prostate cancer deaths (reduction: $38.8 \%$ ). As shown by the expected and observed deaths rates in men older than 80 years, there was a smaller, yet still substantial, decrease in the prostate cancer mortality rate (period 2002 to 2005, men older than 80: 187 expected deaths, 134 observed deaths) (reduction:28.4\%).

\section{DISCUSSION}

This report is based on a demonstration project conducted in the population of Tyrol, Austria, where PSA testing has been offered to men free of charge since 1993. Even without a system of invitation and re invitation, more than 4 men out of 5 aged 45 to 74 years underwent at least one PSA test for screening in the years 1993 to 2005 (table 1).

During the past decade, there has been a dramatic stage migration for newly diagnosed prostate cancer. Currently, $80 \%$ of men are diagnosed with prostate cancer while it is pathologically organ confined, compared to only $20 \%$ to $30 \%$ in the "pre-PSA era" ${ }^{20}$. In the SEER program, the rate of distant disease fell by $52 \%$ 
between 1990 and $1994^{21}$.

A similar favorable stage migration is documented in the Tyrol Project and can almost certainly be attributed, at least in part, to the widespread acceptance of PSA-based prostate cancer screening. Several studies have clearly demonstrated that cancers detected because of a PSA elevation are more likely to be organ confined than those detected because of an abnormal digital rectal examination ${ }^{20-26}$.

Prostate cancer incidence data from Tyrol show that the age-standardized rate for metastatic cancer decreased from 5.2 to 2.1 per 100,000 and for advanced cancer (UICC stage IV) from 7.9 to 3.7 per 100,000 from the period $1988-1992$ to 1998 2002. This is consistent with a population-based, case-control study showing that among asymptomatic men, the frequency of PSA-testing was significantly lower among men with metastatic prostate cancer ${ }^{27}$.

Since PSA thresholds lower than the traditional $4 \mathrm{ng} / \mathrm{ml}$ for recommending a prostate biopsy were adopted, a highly significant increase in the proportion of patients with pathologically organ-confined disease has been observed: this rose from $23.7 \%$ in 1993 to $78.7 \%$ in 2005 . Similar results were reported in a 12-year PSA-based screening study when the pathological features of prostate cancers detected were compared from 3 consecutive time intervals ${ }^{28}$.

Screening for prostate cancer, viewed as the first step in patient management would not lead to an improved outcome if the cancers detected were either clinically 
insignificant, already incurable or if the available treatment options were ineffective. For prostate cancer this has been shown not to be the case. The Scandinavian Prostate Cancer Group Study reported on outcomes of 347 men with early, nonscreen-detected prostate cancer randomized to radical prostatectomy, compared to 348 men randomized to watchful waiting ${ }^{29}$. The risk of overall mortality, cancerspecific mortality, distant metastasis, and local progression were all significantly lower in the patients treated with radical prostatectomy after 8 years of follow-up. After 10 years, there also was a significant improvement in overall survival in patients treated with radical prostatectomy ${ }^{29}$.

It is likely that treatment with the intention to cure for early prostate cancer has contributed to the decreases in prostate cancer mortality observed in countries such as the United States, where treatment with radical prostatectomy and radiation therapy is widely practiced. Extrapolating these findings to a population of men who undergo screening, the removal of small tumors should improve survival by detecting the life-threatening tumors earlier. In the Tyrol screening project, the treatment of patients with clinical stage $\mathrm{T} 1$ or $\mathrm{T} 2$ lesions was radical prostatectomy in $89.3 \%$, performed largely in a high-volume tertiary referral center by experienced surgeons and was associated with low morbidity ${ }^{30}$ (95.1 \% urinary continence (no pads) after 12 months; $78.9 \%$ preservation of erectile potency in men $<65$ years of age). The probability of clinical cancer progression following radical prostatectomy in patients with low PSA levels $(<4 \mathrm{ng} / \mathrm{ml})$, a low positive surgical margin rate $(4.2 \%)$, and a low biochemical recurrence rate $(5.7 \%)$ is low. Therefore, in the long term, patients with early-stage prostate cancer is detected through PSA screening who are treated 
effectively should be expected to have a lower prostate cancer mortality rate.

The controversy surrounding screening for prostate cancer with PSA revolves around three key issues. Does PSA identify clinically significant prostate cancer in the majority of cases? Does aggressive intervention with surgery or radiation alter the outcome in men diagnosed with clinically significant disease? Does diagnosis and treatment seriously impinge of quality of life?

The estimates of prostate cancer "overdiagnosis" (30\% to $50 \%$ ) have been exaggerated in the literature. ${ }^{31,32}$ This may be due in part by the fact that much of the data have been derived from older men, in whom overdiagnosis is a greater concern because of their limited life expectancy. In younger men, who are most likely to benefit from early diagnosis and treatment, the criteria for calling overdiagnosis are much less frequently met $(\sim 15 \%)^{32}$. Nevertheless, a recent study has shown that even men over 65 years of age have a mortality benefit from treatment with radical prostatectomy or radiation therapy ${ }^{33}$. In the Tyrol study, in which the mean age of screened men was less than 65 years, the estimate of overdiagnosis according to the criteria of Epstein ${ }^{34}$ was 8,7 \% ${ }^{35}$.

Using the pathology criteria in the prostatectomy specimen for overdiagnosis of pathologic stage T2a, Gleason $<7$, overdiagnosis in the Tyrol Project was $19.7 \%$ in the PSA range of $2 \mathrm{ng} / \mathrm{ml}$ to $4 \mathrm{ng} / \mathrm{ml}$ and $17.6 \%$ in the PSA range of $2 \mathrm{ng} / \mathrm{ml}$ to 10 $\mathrm{ng} / \mathrm{ml}^{34}$. In another screening study, using the Ohori criteria for unimportant disease ${ }^{25}$, fewer than $10 \%$ of men underwent treatment for "overdiagnosed" prostate 
cancer $^{36}$.

Although reduction in prostate cancer mortality rates are important, it is also necessary to consider the effects of prostate cancer screening and treatment on patient quality of life. Potential gains in survival could be more than offset by decrements in quality of life that may result from diagnosis and treatment ${ }^{37}$. Ecological data suggest that $10 \%$ to $30 \%$ of the geographic variation in mortality rates may relate to variations in access to medical care ${ }^{38}$. A key feature of this study setting is that patients in Tyrol have equal access to all therapeutic resources (surgery, radiotherapy and hormonal therapy) and that diagnosis and therapy are free of charge for everyone.

Population-based reductions in prostate cancer mortality rates may be the only way to assess the impact of prostate cancer screening. Although androgen-deprivation therapy can slow the progression of prostate cancer, as a curative treatment for advanced disease is not available yet, any reduction in mortality is likely attributable, at least in part, to programs that detect prostate cancer at an early stage and prevent the tumor acquiring the lethal phenotype. Since PSA screening was widely implemented in 1990, prostate cancer mortality in the United States has decreased dramatically. The prostate cancer mortality rate has decreased by an average of 2.4\% yearly from 1993 to $2003^{3}$. Between 1993 and 2002, the truncated (40-79) age standardised prostate cancer mortality rate in the United States has decreased by an average of $4.7 \%$ per year. In Austria, excluding Tyrol, the decline was $3.2 \%$ per year while in the Tyrol it was $7.3 \%$. The dramatic shift of stage in the PSA era 
followed by effective therapy should translate into a decrease of mortality.

Data from the Tyrol have been presented here using the same approach as in the previous report ${ }^{19}$ for the purpose of maintaining longitudinal transparency of our study findings. These findings continue to be consistent with the notion that making PSA testing freely available, and its wide acceptance by men in the population, is associated with a reduction in prostate cancer mortality in a region where potentially curative prostate cancer treatment services are available free of charge to all patients.

Although it is not possible from the available data to separate the individual contributions of PSA testing and curative treatment to the favorable outcomes, the more rapid accelerated decline in mortality rates in Tyrol compared to the rest of Austria is unlikely to be artefactual. The delay between early detection and radical treatment beginning in 1988 (accelerating in 1993) and the decline in mortality in the targeted age range which started in 1996, is comparable with that seen in other screening programs with high compliance. It is likely that much of this decline in mortality rates is due to earlier detection and successful treatment of prostate cancer. However, an important corollary implication of our study is that screening is only the first step in the optimal management of prostate cancer patients.

Pending the results of the large randomized clinical trials, there is a great public health need to know more details of the potential risks and benefits of PSA testing. However, it is likely that, given the penetrance of PSA testing in communities of men, 
even null findings from these randomised trials will not deter future PSA testing rates $^{37}$.

The study group described here is a well-defined population of Tyrol, where detailed knowledge of PSA testing rates and information on therapy offered to the population exist. Of course, the design of our study cannot overcome the problems inherent in non-randomized studies, but it can provide useful information on the potential benefits of early detection in a real-life setting.

\section{Acknowledgements}

It is a pleasure to acknowledge the contribution of all participants to this study. This manuscript is published by the list authors on behalf of the Tyrol Prostate Cancer Screening Group comprising General Practitioners in the Federal State of Tyrol, the Urologists Arno Ebner, Stephan Frank, Otmar Ennemoser, Lorenz Hoeltl, Jörg Joost, Sandor Kovesdi, Heinz Puschban, Wolfgang Schachtner, Karl Scheiber, Ferdinand Walser, Gerhard Weissteiner, Ernst Zangerl, Markus Sandbichler, Josef Girstmaier, Günther Petrischor, the Pathologists Gregor Mikuz, Georg Schäfer and Andrea Brunner, medical laboratories, all doctors, nurses and secretaries of the Department of Urology of the University of Innsbruck, the Blood Bank of the Red Cross, the Innsbruck, Social Security and Health Service of the Federal State Tyrol, Military Hospital Innsbruck, Staffregiment No. 6 of the Austrian Military Forces, Landeck, Works' Medical Officers of the Post and Telecom, Innsbruck, Austria, Plansee 
Company, Swarovski Company, Social Security Board of Kematen and Jenbach, District Commission of Schwaz. 
Table 1

Annual Uptake rates of PSA Testing in Tyrol in Age Group 45-74 Years

\begin{tabular}{|c|c|c|c|c|}
\hline & $\begin{array}{l}\text { Men with } \\
\text { PSA } \\
\text { screening } \\
\text { test }\end{array}$ & $\begin{array}{c}\text { Male } \\
\text { Population }\end{array}$ & $\begin{array}{l}\text { Testing } \\
\text { rate }\end{array}$ & $\begin{array}{l}\text { Cumulative } \\
\text { Testing rate }\end{array}$ \\
\hline 1993 & 9,474 & 86,067 & $11.0 \%$ & $11.0 \%$ \\
\hline 1994 & 14,147 & 88,342 & $16.0 \%$ & $23.3 \%$ \\
\hline 1995 & 20,309 & 90,153 & $22.5 \%$ & $34.6 \%$ \\
\hline 1996 & 23,839 & 91,497 & $26.1 \%$ & $44.1 \%$ \\
\hline 1997 & 26,796 & 92,607 & $28.9 \%$ & $51.0 \%$ \\
\hline 1998 & 30,228 & 93,719 & $32.3 \%$ & $56.8 \%$ \\
\hline 1999 & 36,366 & 95,000 & $38.3 \%$ & $63.3 \%$ \\
\hline 2000 & 41,860 & 96,692 & $43.3 \%$ & $70.1 \%$ \\
\hline 2001 & 44,400 & 98,638 & $45.0 \%$ & $75.1 \%$ \\
\hline 2002 & 50,370 & 100,740 & $50.0 \%$ & $80.2 \%$ \\
\hline 2003 & 51,658 & 102,904 & $50.2 \%$ & $84.0 \%$ \\
\hline 2004 & 52,503 & 105,216 & $49.9 \%$ & $86.1 \%$ \\
\hline 2005 & 46,591 & 107,600 & $43.3 \%$ & $86.6 \%$ \\
\hline
\end{tabular}




\section{Table 2}

RADICAL PROSTATECTOMY: MORBIDITY AND MORTALITY, 1988 - 2004 : 1.663 patients

\begin{tabular}{|c|c|c|}
\hline Mortality (30 days) & $n=1663$ & $0 \%$ \\
\hline Rectal injury & $n=1663$ & $0.6 \%$, since 2000: $0.1 \%$ \\
\hline Ureteral injury & $n=1663$ & $0.0 \%$ \\
\hline Bleedings requiring intervention & $n=1663$ & $0.7 \%$ \\
\hline Continence (no pads) & & \\
\hline (3 months postop.) & & $95.1 \%$ \\
\hline Potency < 65 years, since 2000 & $n=512$ & $80.6 \%$ \\
\hline
\end{tabular}


Table 3

Observed and Expected numbers of Prostate cancer deaths in Tyrol and the rest of Austria for men aged 40-79 and 80+.[Expected values are based on the application of age-specific rates from 1986-1990 to the population].

\begin{tabular}{|c|c|c|c|c|c|c|c|c|c|c|}
\hline \multirow[t]{3}{*}{ Aged 40-79 } & \multirow[b]{3}{*}{ Deaths } & \multirow{3}{*}{\begin{tabular}{l}
\multicolumn{1}{c}{ Tyrol } \\
Expected \\
Deaths
\end{tabular}} & \multirow[b]{3}{*}{ SMR } & \multicolumn{2}{|c|}{ 95\% Confidence } & \multicolumn{3}{|c|}{ Rest of Austria } & \multicolumn{2}{|c|}{ 95\% Confidence } \\
\hline & & & & \multirow{2}{*}{$\begin{array}{l}\text { Lower } \\
\text { Limit }\end{array}$} & \multirow{2}{*}{$\begin{array}{l}\text { Upper } \\
\text { Limit }\end{array}$} & \multicolumn{3}{|c|}{ Expected } & Lower & \multirow{2}{*}{$\begin{array}{l}\text { Upper } \\
\text { Limit }\end{array}$} \\
\hline & & & & & & Deaths & Deaths & SMR & Limit & \\
\hline 1991 & 50 & 44.1 & 113.4 & 84.1 & 149.5 & 606 & 544.5 & 111.3 & 102.6 & 120.5 \\
\hline 1992 & 44 & 43.6 & 100.8 & 73.3 & 135.4 & 546 & 538.6 & 101.4 & 93.1 & 110.3 \\
\hline 1993 & 52 & 43.2 & 120.4 & 89.9 & 157.9 & 554 & 534.7 & 103.6 & 95.2 & 112.6 \\
\hline 1994 & 42 & 43.4 & 96.8 & 69.8 & 130.9 & 489 & 536.8 & 91.1 & 83.2 & 99.5 \\
\hline 1995 & 45 & 44.8 & 100.4 & 73.2 & 134.4 & 516 & 552.3 & 93.4 & 85.5 & 101.8 \\
\hline 1996 & 37 & 47.1 & 78.6 & 55.3 & 108.3 & 543 & 580.2 & 93.6 & 85.9 & 101.8 \\
\hline 1997 & 33 & 49.7 & 66.4 & 45.7 & 93.3 & 559 & 611.9 & 91.4 & 83.9 & 99.3 \\
\hline 1998 & 30 & 52.3 & 57.4 & 38.7 & 81.9 & 575 & 641.4 & 89.6 & 82.5 & 97.3 \\
\hline 1999 & 37 & 54.8 & 67.6 & 47.6 & 93.1 & 602 & 664.6 & 90.6 & 83.5 & 98.1 \\
\hline 2000 & 32 & 56.8 & 56.4 & 38.6 & 79.6 & 606 & 680.8 & 89.0 & 82.1 & 96.4 \\
\hline 2001 & 44 & 57.5 & 76.5 & 55.6 & 102.7 & 571 & 679.1 & 84.1 & 77.3 & 91.3 \\
\hline 2002 & 44 & 59.2 & 74.3 & 54.0 & 99.7 & 78 & 689.2 & 83.9 & 77.2 & 91.0 \\
\hline 2003 & 32 & 61.2 & 52.3 & 35.8 & 73.8 & 537 & 694.0 & 77.4 & 71.0 & 84.2 \\
\hline 2004 & 28 & 63.3 & 44.2 & 29.4 & 63.9 & 549 & 714.6 & 76.8 & 70.5 & 83.5 \\
\hline 2005 & 30 & 65.3 & 45.9 & 31.0 & 65.6 & 517 & 730.0 & 70.8 & 64.9 & 77.2 \\
\hline \multirow{3}{*}{$\begin{array}{l}\text { Aged 80+ } \\
\text { Year }\end{array}$} & & \multirow{3}{*}{\begin{tabular}{l}
\multicolumn{1}{c}{ Tyrol } \\
Expected \\
Deaths
\end{tabular}} & & \multicolumn{2}{|c|}{$95 \%$ Confidence } & \multirow{2}{*}{\multicolumn{3}{|c|}{$\begin{array}{l}\text { Rest of Austria } \\
\text { Expected }\end{array}$}} & \multicolumn{2}{|c|}{$95 \%$ Confidence } \\
\hline & & & & Lower & Upper & & & & Lower & Upper \\
\hline & Deaths & & SMR & Limit & Limit & Deaths & Deaths & SMR & Limit & Limit \\
\hline 1991 & 46 & 39.7 & 115.8 & 84.8 & 154.5 & 504 & 451.7 & 111.6 & 102.0 & 121.8 \\
\hline 1992 & 47 & 41.6 & 113.0 & 83.0 & 150.2 & 502 & 465.0 & 107.9 & 98.7 & 117.8 \\
\hline 1993 & 44 & 43.3 & 101.7 & 73.9 & 136.6 & 527 & 479.7 & 109.9 & 100.7 & 119.7 \\
\hline 1994 & 53 & 44.6 & 118.7 & 88.9 & 155.3 & 504 & 491.5 & 102.5 & 93.8 & 111.9 \\
\hline 1995 & 48 & 44.9 & 106.9 & 78.8 & 141.7 & 593 & 494.6 & 119.9 & 110.4 & 130.0 \\
\hline 1996 & 54 & 44.1 & 122.6 & 92.1 & 159.9 & 535 & 484.4 & 110.4 & 101.3 & 120.2 \\
\hline 1997 & 55 & 43.2 & 127.3 & 95.9 & 165.7 & 537 & 471.1 & 114.0 & 104.6 & 124.1 \\
\hline 1998 & 30 & 42.4 & 70.8 & 47.7 & 101.0 & 504 & 459.7 & 109.6 & 100.3 & 119.6 \\
\hline 1999 & 42 & 42.7 & 98.5 & 71.0 & 133.1 & 541 & 457.5 & 118.2 & 108.5 & 128.6 \\
\hline 2000 & 47 & 43.7 & 107.4 & 78.9 & 142.9 & 544 & 472.6 & 115.1 & 105.6 & 125.2 \\
\hline 2001 & 41 & 42.7 & 95.9 & 68.8 & 130.1 & 528 & 466.8 & 113.1 & 103.7 & 123.2 \\
\hline 2002 & 35 & 44.0 & 79.5 & 55.3 & 110.5 & 481 & 486.5 & 98.9 & 90.2 & 108.1 \\
\hline 2003 & 36 & 45.5 & 79.0 & 55.4 & 109.4 & 553 & 489.8 & 112.9 & 103.7 & 122.7 \\
\hline 2004 & 31 & 47.7 & 65.0 & 44.1 & 92.2 & 531 & 527.4 & 100.7 & 92.3 & 109.6 \\
\hline 2005 & 32 & 49.9 & 64.1 & 43.8 & 90.5 & 518 & 556.4 & 93.1 & 85.2 & 101.5 \\
\hline
\end{tabular}




\section{Legends for figures:}

Fig. 1: Tyrol Prostate Cancer Demonstration Project: Evolution of early detection algorithm.

Fig. 2: $\quad$ Tyrol Prostate Cancer Demonstration Project: Evolution of diagnostic work up.

Fig. 3: $\quad$ Prostate Cancer Incidence Rates per 100,000 by tumour stage in the county of Tyrol and the Republic of Austria excluding the county of Tyrol

Fig. 4: $\quad$ Prostate Cancer Mortality rates men aged 40-79 in the county of Tyrol and in the Republic of Austria excluding the county of Tyrol 
Fig. 1: Tyrol Prostate Cancer Demonstration Project: Evolution of early detection algorithm.

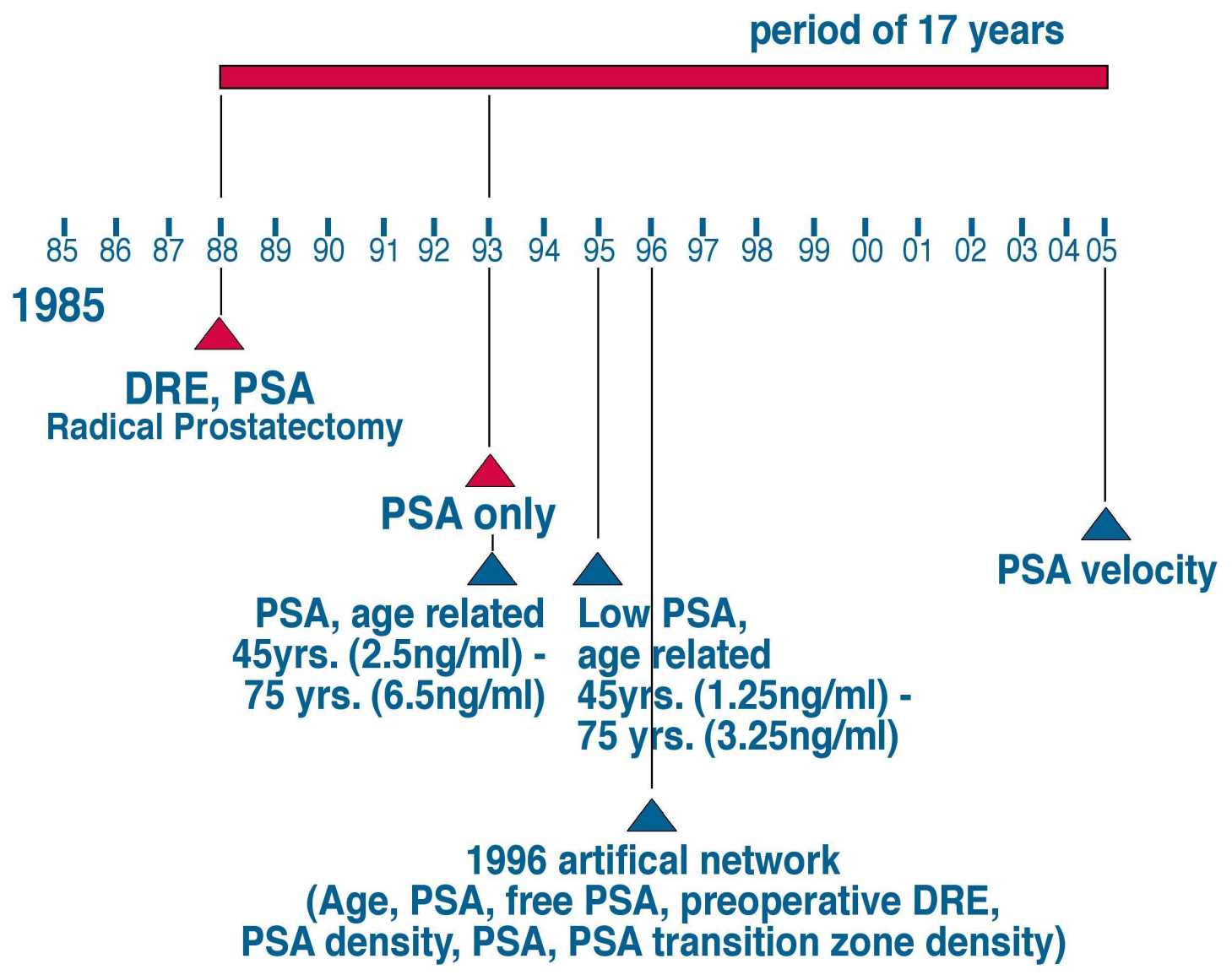


Fig. 2: Tyrol Prostate Cancer Demonstration Project: Evolution of diagnostic work up.

\section{period of 17 years}

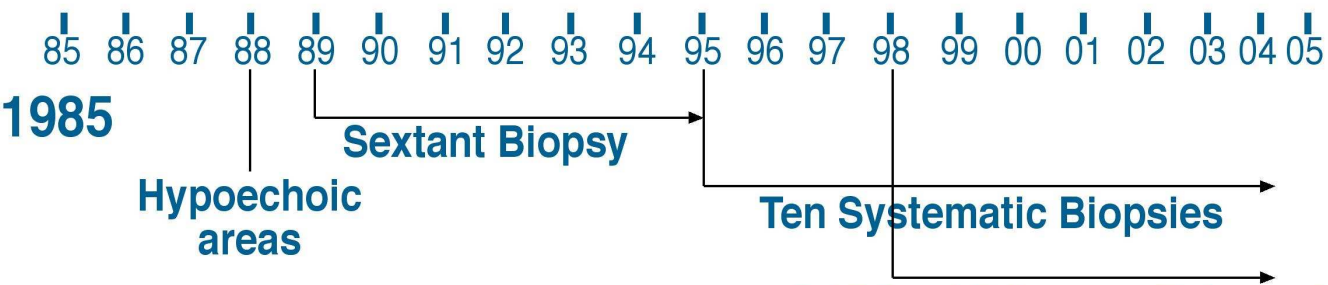

Additional 5 Contrast-Enhanced-ColourDoppler-Ultrasound Biopsies 
Fig. 3: $\quad$ Prostate Cancer Incidence Rates per 100,000 by tumour stage in the county of Tyrol and the Republic of Austria excluding the county of Tyrol

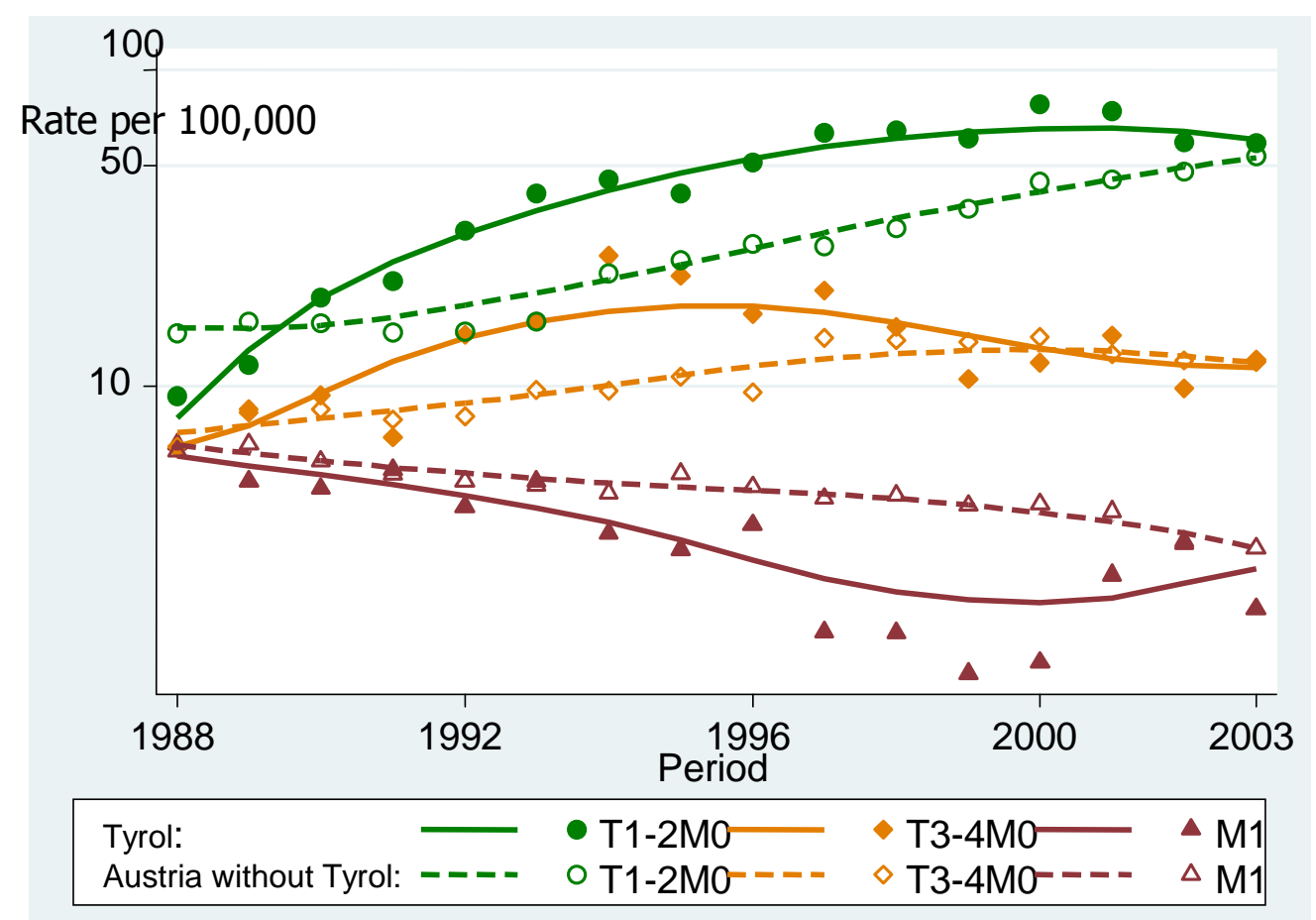


Figure 4 (a) Age standardised mortality rates and Predictions from a GAM model separate smoothing trend in Tyrol and Rest of Austria

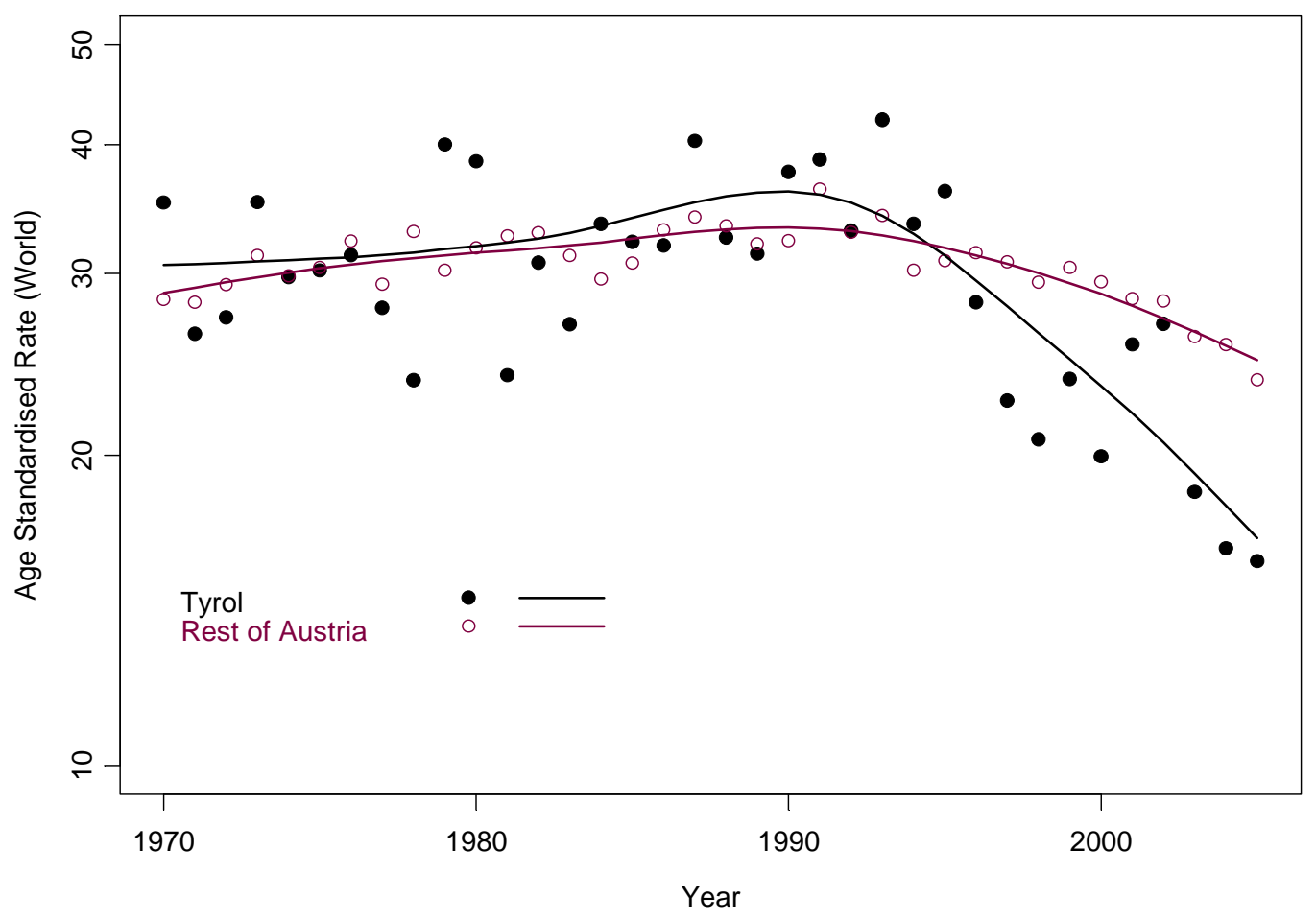


Figure 4 (b) Age standardised mortality rates and Predictions based upon linear change point model with Age interactions

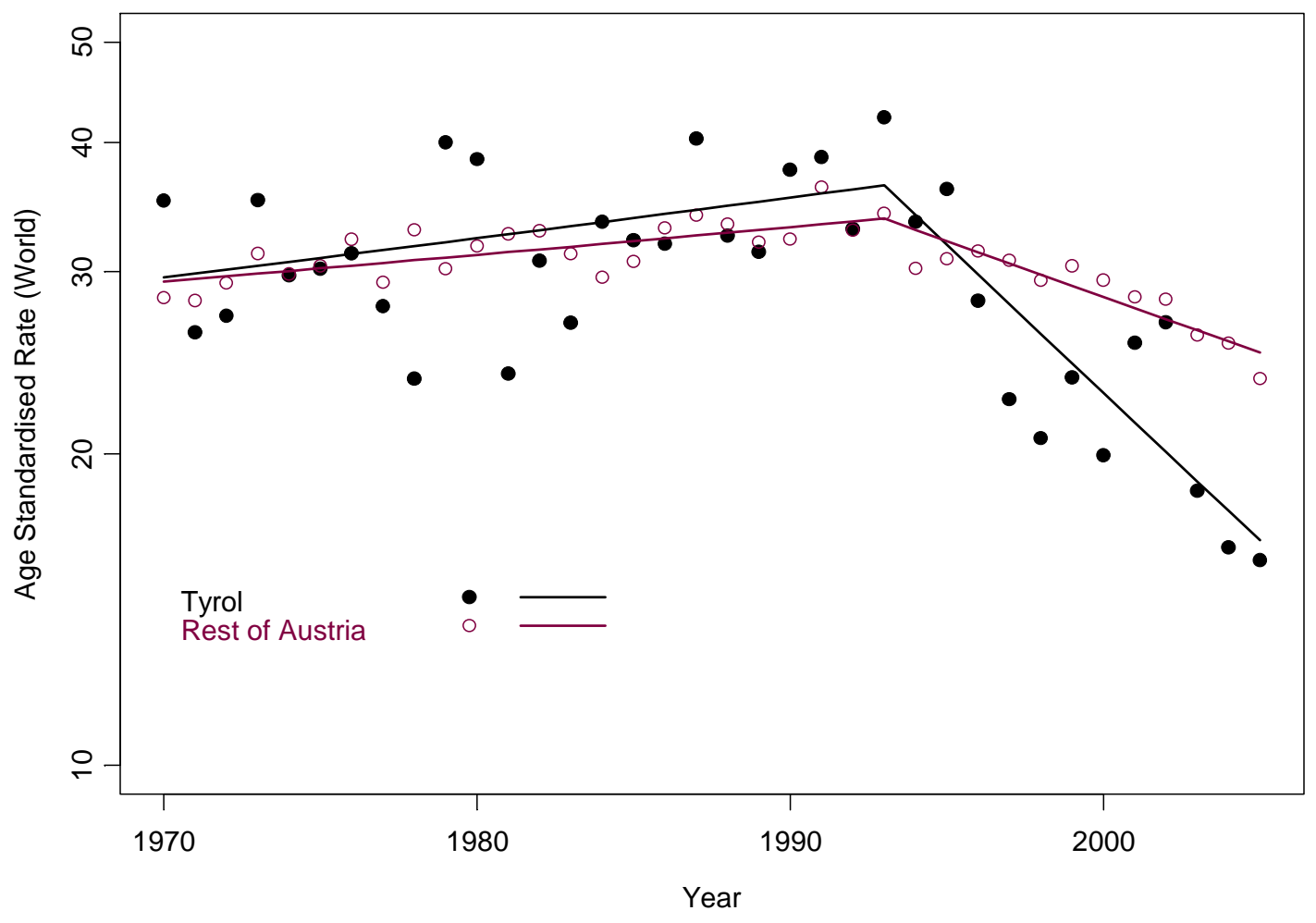




\section{REFERENCES}

1. Institute UNC: http://www.cancer.gov/.

2. Parkin DM, Bray F, Ferlay J and Pisani P: Global cancer statistics, 2002. CA Cancer J Clin.2005, 55: 74-108.

3. Jemal A, Murray T, Samuels A, Ghafoor A, Ward E and Thun MJ: Cancer statistics, 2003. CA Cancer J Clin.2003, 53: 5-26.

4. Boring CC, Squires TS and Tong T: Cancer statistics, 1993. CA Cancer J Clin. 1993, 43: 7-26.

5. Gohagan JD, Prorok PC, Kramer BS et al. The Prostate, Lung, Colorectal, and Ovarian Cancer Screening Trial of the National Cancer Institute. Cancer. 1995, 75: $1869-1873$.

6. de Koning HJ, Auvinen A, Berenguer Sanchez A, Calais da Silva F, Ciatto S, Denis L, Gohagan JK, Hakama M, Hugosson J, Kranse R et al:: Large-scale randomized prostate cancer screening trials: program performances in the European Randomized Screening for Prostate Cancer trial and the Prostate, Lung, Colorectal and Ovary cancer trial. Int J Cancer2002, 97: 237-244.

7. de Koning $\mathrm{HJ}$, Liem MK, Baan CA, Boer R, Schroder FH and Alexander FE: Prostate cancer mortality reduction by screening: power and time frame with 
complete enrolment in the European Randomised Screening for Prostate Cancer (ERSPC) trial. Int J Cancer. 2002, 98: 268-73.

8. Lujan M, Paez A, Pascual C, Angulo J, Miravalles E, Berenguer A: Extend of Prostate Specific antigen contamination in the Spanish section of the European randomized study of screening for Prostate Cancer(ERSPC). European Urology 2006,50: 1234-1240.

9. Zelen M :Are primary Cancer prevention trials feasible? J Natl Cancer Inst 1988, 80: $1442-1444$.

10. Oesterling JE, Jacobsen SJ, Chute CG, et al. Serum prostate-specific antigen ina community-based population of healthy men. JAMA 1993, 270:860-864.

11. Horninger W, Berger AP, Pelzer A, Bektic J, Klocker H, Oberaigner W, Schönitzer D, Severi G, Robertson C, Boyle P and Bartsch G. Amer J Urology Review 2005, 4, No 4, 172-175.

12. Berger AB, Deibl M, Steiner $H$, Bektic J, Pelzer A, Spranger R, Klocker H, Bartsch G and Horninger W. Longitudinal PSA Changes in Men With and Without Prostate Cancer: Assessment of Prostate Cancer Risk. The Prostate 2005, 64:240-245. 
13. Frauscher F, Klausner A, Halpern E, Horninger W and Bartsch G. Detection of prostate cancer with a microbubble ultrasound contrast agent.. Lancet 2001, 357: $1849-1850$.

14. Walsh PC: Anatomic radical prostatectomy: evolution of the surgical technique. J Urol. 1988, 160: 2418-24.

15. Boyle P, Parkin DM: Statistical methods for registries. In: Jensen OM ,McLennan R et al(Eds) Cancer Registration: Principles and Methods. pp 126-158 IARC Scientific Publication No. 95. Lyon, 1995.

16. McCullagh $\mathrm{P}$ and Nelder JA: Generalized Linear Models, $2^{\text {nd }}$ ed. London, Chapman and Hall,1989.

17. Hastie, T. and Tibshirani, R. Generalized Additive Models. Chapman and Hall, London, 1990

18. Splus 2000: Users Guide. Seattle, Data Analysis Products Division, Mathsoft 1999.

19. Bartsch G, Horninger W, Klocker H, Reissigl A, Oberaigner W, Schönitzer D, Severi G, Robertson C and Boyle P: Prostate cancer mortality after introduction of prostate-specific antigen mass screening in the Federal State of Tyrol, Austria. 2001, Urology. 58: 417-24. 
20. Catalona WJ, Smith DS, Ratliff TL and Basler JW: Detection of organ-confined prostate cancer is increased through prostate-specific antigen-based screening. JAMA. 1993, 270: 948-54.

21. Stephenson RA: Population-based prostate cancer trends in the PSA era: data from the surveillance, epidemiology, and end results (SEER) program. Monogr Urol. 1998, 19: 3-19.

22. Smith DS and Catalona WJ: The nature of prostate cancer detected through prostate specific antigen based screening. 1994, J Urol. 152: 1732-6.

23. Mettlin C, Murphy GP, Lee F, Littrup PJ, Chesley A, Babaian R, Badalament R, Kane RA and Mostofi FK: Characteristics of prostate cancers detected in a multimodality early detection program. The Investigators of the American Cancer Society-National Prostate Cancer Detection Project. Cancer. 1993, 72: $1701-8$.

24. Scaletscky R, Koch MO, Eckstein CW, Bicknell SL, Gray GF, Jr. and Smith JA, Jr.: Tumor volume and stage in carcinoma of the prostate detected by elevations in prostate specific antigen. J Urol. 1994, 152: 129-31. 
25. Ohori M, Wheeler TM, Dunn JK, Stamey TA and Scardino PT: The pathological features and prognosis of prostate cancer detectable with current diagnostic tests. J Urol. 1994, 152: 1714-20.

26. Gerber GS, Thisted R, Chodak GW and Thompson IM: Disease-specific survival following routine prostate cancer screening by digital rectal examination: corrected patient classification. JAMA. 1993,270: 2437.

27. Kopec JA, Goel V, Bunting PS, Neuman J, Sayre EC, Warde P, Levers P and Fleshner N: Screening with prostate specific antigen and metastatic prostate cancer risk: a population based case-control study. J Urol. 2005, 174: 495-9; discussion 499.

28. Loeb S, Gonzalez CM, Roehl KA, Han M, Antenor JA, Yap RL and Catalona WJ: Pathological characteristics of prostate cancer detected through prostate specific antigen based screening. J Urol. 2006, 175: 902-6.

29. Bill-Axelson A, Holmberg L, Ruutu M, Haggman M, Andersson SO, Bratell S, Spangberg A, Busch C, Nordling S, Garmo H et al:: Radical prostatectomy versus watchful waiting in early prostate cancer. N Engl J Med. 2005, 352: 1977-84. 
30. Horninger $\mathrm{W}$, Strasser $\mathrm{H}$ and Bartsch G: Radical retropubic prostatectomy: apical preparation and curtain dissection of the neurovascular bundle. BJU Int. 2005, 95: 911-23.

31. Etzioni R, Penson DF, Legler JM, di Tommaso D, Boer R, Gann PH and Feuer EJ: Overdiagnosis due to prostate-specific antigen screening: lessons from U.S. prostate cancer incidence trends. J Natl Cancer Inst. 2002, 94: 981-90.

32. Draisma G, Boer R, Otto SJ, van der Cruijsen IW, Damhuis RA, Schroder FH and de Koning $\mathrm{HJ}$ : Lead times and overdetection due to prostate-specific antigen screening: estimates from the European Randomized Study of Screening for Prostate Cancer. J Natl Cancer Inst.2003, 95: 868-78.

33. Wong Yu-N, Mitra M, Hudes G, Localio R, Schwartz J S, Wan F, Montagnet Ch, Armstrong K: Survival associated with treatment vs. observation of localized prostate cancer in elderly men. JAMA 2006, 296: 2683-93.

34. Epstein JI, Chan DW, Sokoll L, Walsh PC, Cox JL, Rittenhouse H, Wolfert R and Carter HB: Nonpalpable stage T1c prostate cancer: prediction of insignificant disease using free/ total prostate specific antigen levels and needle biopsy findings. J Urol 1998;160:2407-11. 
35. Bartsch G, Horninger W, Oberaigner W, Schönitzer D, Klocker H, Robertson C, Severi G, Boniol M and Boyle P. Tyrolean Screening Study: Update 2005 - stage migration and decrease of mortality. Journal of Urology, 2006, 175 Suppl., 2006

36. Graif Th,Yu X, Loeb St, Gashti SN, Griffin Ch, Han M, Roehl KA, Suarez BK, Catalona WJ: Underdiagnosis and overdiagnosis of prostate cancer. J Urol 175, No. 4, Suppl., 2006

37. Boyle P. Screening for prostate cancer: have you had your cholesterol measured? BJU International, 2003, 92, 191-199

38. Jemal A, Ward E, Wu X, Martin HJ, McLaughlin CC and Thun MJ: Geographic patterns of prostate cancer mortality and variations in access to medical care in the United States. Cancer Epidemiol Biomarkers Prev. 2005, 14: 590-5. 